\title{
Pathogenesis of the Acute Pulmonary Edema Occurring after Brain Operation and Brain Trauma
}

\author{
Miyoshi URABE, M.D., ${ }^{*}$ Yasuo SEGAWA, M.D., \\ Takashi TSUBOKAWA, M.D., Keiichi YAMAMOTO, M.D., \\ Kinpei ARAKI, M.D., and Kaiichi IZUMI, M.D.
}

\begin{abstract}
By investigating the autopsy cases as well as clinical cases, it was found that the occurrence of the pulmonary edema following the brain damage was higher when it was compared with that of other diseases. In addition, clinical cases of the pulmonary cdema occurring after various operations have been studied in detail and classified into 3 groups: (1) that occurring after brain operation and brain trauma, (2) that occurring after cardiopulmonary operation of cases with pulmonary circulatory disturbances, (3) that occurring after abdominal operation of cases with metabolic disorders. In order to clarify the mechanisms of occurrence of the pulmonary edema, studies were undertaken on the pulmonary vascular innervation and a pulmonary edema of the central nervous system in origin was experimentally produced. Examining the pathophysiology of the pulmonary edema in detail, some knowledges have been obtained about pathogenesis of an acute postoperative pulmonary edema.
\end{abstract}

\begin{abstract}
QTUDY of an acute pulmonary edema occurring after brain operations $\checkmark$ and brain traumas is one of the very difficult problems. ${ }^{1-7}$ Despite the extensive studies in the past, the mechanism of its occurrence has not been well elicited. ${ }^{6,8)-18}$ One of the reasons for the failure in clarifying the mechanism is that the occurrence of pulmonary edema is too rapid and too severe to make clinical investigation in detail. Another reason is that it is extremely difficult to produce pulmonary edema experimentally as exactly the same as in postoperative cases. ${ }^{19-25)}$ After many attempts we have finally overcome these difficulties and succeeded in clarifying the pathogenesis of the postoperative pulmonary edema, especially that occurring after brain operation as well as brain trauma both clinically and experimentally.
\end{abstract}

From the First Department of Surgery, Faculty of Medicine, University of Kanazawa, Kanazawa.

* Professor of Surgery. 


\section{Materials and Methods}

1) Analysis of autopsy cases as well as clinical cases of the acute pulmonary edema

The statistical analysis was carried out in a total of 1,355 autopsy cases at the Pathological Department, University of Kanazawa.

46 clinical cases of the pulmonary edema were studied morphologically (Table II). They consist of 35 cases of the acute postoperative pulmonary edema from 1,389 operations and 11 cases of the acute pulmonary edema as a complication of the cerebral trauma which were dealt with at the Department of Medical Jurisprudence, University of Kanazawa (Table III).

2) Methods for studying the innervation of the pulmonary vessels

Twenty-five adult dogs were used for the experiments. Under the anesthesia of intramuscular injection of Ravonal $30 \mathrm{mg}$./Kg., the animal was stabilized in a stereotaxical apparatus. The right heart catheterization was done for recording the pulmonary arterial pressure. The craniotomy was made. A stimulating electrode was inserted into several portions of the brain of the dog. The electrode was a coaxial needle with enamel coating, made of stainless steel, $1 \mathrm{~mm}$. in diameter. As the stimulation, the squarc wave pulses of 15 volts, 100-120 c.p.s., and 1 msec. were used for 15,30 or 60 seconds. The alteration of the pulmonary arterial pressure subsequent to the stimulation was recorded through the catheter in the pulmonary artery. The systemic arterial pressure and respiration were simultaneously recorded. The efferent pathway in the innervation of the pulmonary vessels was traced by observing the responses of the pulmonary arterial pressure to the stimulation, when the vagus nerve, the spinal cord and the brain stem were severed at the several levels. The afferent pathway in the innervation of the pulmonary vessels was traced in the following way: a pair of hooks of silver wire was placed on the pulmonary branches of the vagus nerve for the stimulation, which was the square wave of $0.2 \mathrm{msec}$. in duration delivered from the isolation unit. A silver electrode of tip diameter 5-10 $\mu$ with glass coating was inserted in several portions of the medulla, and the evoked potential was picked up subsequent to the stimulation. The electrodes, used both for the stimulation and for the pick-up of the evoked potential were put on a direct electric current, and necrotic foci were made electrolytically at the tip of the electrodes. Thus the sites of the stimulation and the pick-up were determined anatomically after sacrificing the animals.

3) Experimental production of the pulmonary edema of cerebral origin

Under the frontal craniotomy, the electrode $5 \mathrm{~mm}$. in diameter was inserted into the preoptic area and bilateral preoptic areas were completely destroyed by electrocoagulation with an electric current of $7 \mathrm{~mA}$. for $15-20$ seconds. ${ }^{26-283}$ The characteristic type of the pulmonary edema was successfully produced by this procedure.

4) Methods for studying pathophysiology of the experimental pulmonary edema The following methods werc used for the measurement pertinent to the study 
of pathophysiology. Pulmonary circulation; right heart catheterization. Pulmonary circulation time and pulmonary blood volume; Stewart's method using $\mathrm{P}^{82}$ labelled red cells. Plasma colloidal osmotic pressure; Biuret's method and Wells \& Youman's formula. Circulating blood volume; $\mathrm{P}^{32}$ labelled red cells. Extracellular fluid volume; Crandal \& Anderson's method. Tissue water volume; Eaton's method. Electrolytes in plasma, urine and tissue; $\mathrm{Na}, \mathrm{K}$ : flame photometer, Cl: Schales \& Schales's method. Water exchange in the lung; pulmonary dilution curve by $\mathrm{P}^{32}$ and $\mathrm{Na}^{24}$ and Aviado's method. Pulmonary lymphatic flow amount; direct measurement by means of canulation into the right lymph duct. Behaviors of reticular fiber of the alveolar wall; silver impregnation. Permeability of the pulmonary capillary; injection of trypan blue into the pulmonary artery. VDM (Ferritin) in blood and liver tissue; electrophotometry using $\alpha, \alpha^{\prime}$-dipyridyl. Activity of fibrinolytic ferment; MacFarlane's method. Histamine amount in the lung; Satake's bioassay method. Free catecholamine in urine; Euler-Floding's method. Antidiuretic hormone in blood; Lloyed \& Lobotsky's method. 17-OHCS in blood; Sweet \& Takeda's method. 17-KS in urine; Holtroff \& Koch's method. Renal circulation; sodium paraminohippurate and sodium thiosulfate clearance method by Smith's continued dropping injection. Hepatic circulation; Bradley's method. Activity of phosphatase in the lung and liver tissue; staining by a modified method of Gomori. Activity of 5-nucleotidase; McManus's staining. RNA : staining by Kurnick's pyronin-methylgreen method and Feulgen's method. Activity of lipase; a modified method of Gomori using Tween 20, 40, 60 and 80. Polysaccharides in tissue; McManus's PAS staining. Glycogen in tissue; Bensley's method. Lipid in tissue; Daddi's sudan III staining, Herxheimer's sudan IV staining and Lisbon's sudan black B staining. Fatty acid; histochemical method by Okamoto, Ueda \& Kato and round paper chromatography by Kurono.

\section{Results}

\section{Observations of Autopsy Cases (Table I)}

A total of 1,355 autopsy cases died of various diseases were reviewed and investigated the incidence of combination of the pulmonary edema. Eight per cent of those who died of abdominal diseases were accompanied by the pulmonary edema, while $28 \%$ of those who died of organic lesions of the brain had the pulmonary edema. Most of the lesions of the brain accompanying the pulmonary edema were located near or around the internal capsule, the lentiform nucleus and the third ventricle of the brain. Accordingly, it may be assumed that some lesions in these areas of the brain might have something to do with the development of the pulmonary edema.

II. Classification of Clinical Cases of Postoperative Pulmonary Edema (Table II)

Though an acute pulmonary edema appeared in a very wide variety of conditions, it was classified into 3 groups according to the similarity of the histological findings in our 46 cases: (1) that occurring after a brain 
Table I. Incidence of Pulmonary Edema in Autopsy Cases

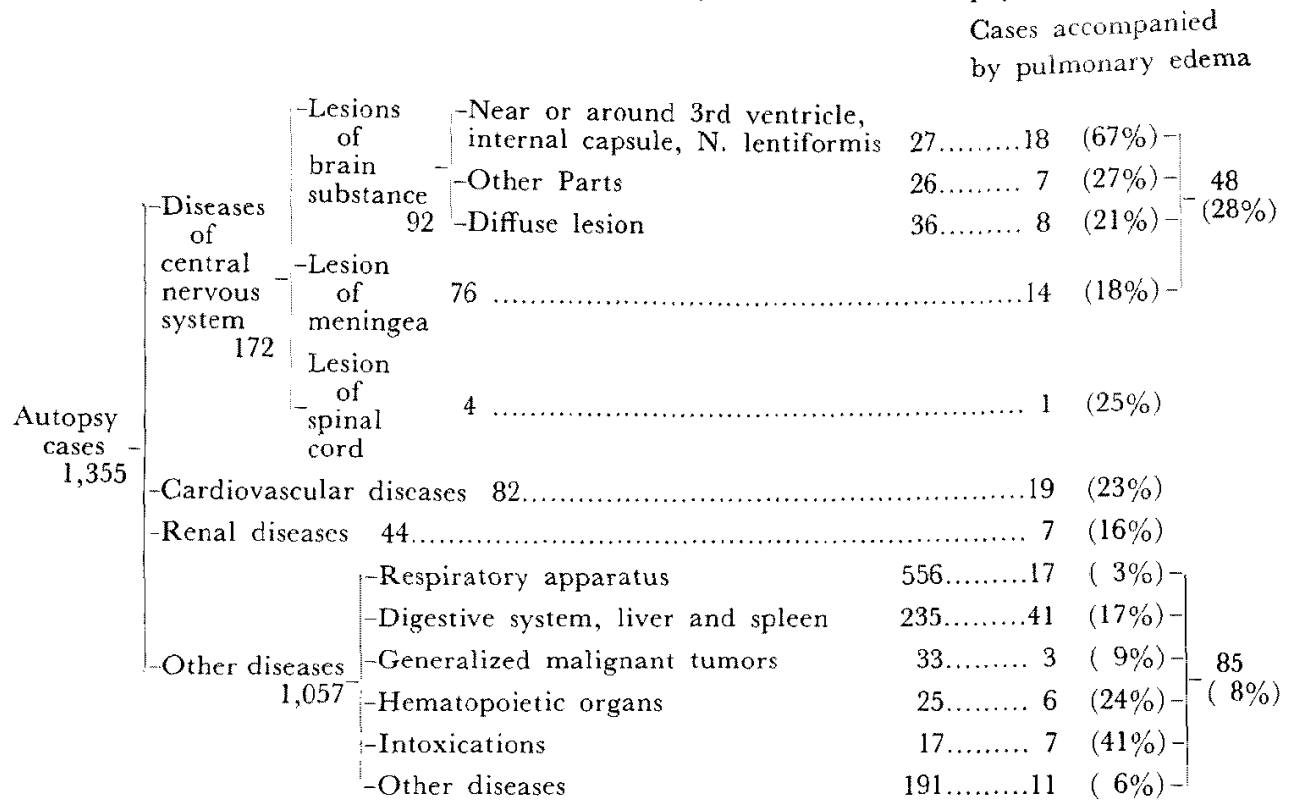

operation as well as brain trauma, (2) that occurring after an operation of cases with cardiopulmonary diseases accompanied by pulmonary circulatory disturbances, and (3) that occurring after an abdominal operation of various diseases accompanied by metabolic disorder such as hypoalbuminemia, anemia and hepatic or renal disturbance.

Table II. Classification of Clinical Cases of Postoperative Pulmonary Edema

1st Group: Those accompanied by nervous disturbance 19 Cases

2nd Group: Those accompanied by pulmonary circulatory disturbance 19 Cases

3rd Group: Those accompanied by metabolic disorder

8 Cases Total 46 Cases

As to the features of the pulmonary edema occurring after an operation for diseases of the central nervous system, there appeared a marked congestion of the pulmonary vascular system and floating of red cells was found in the alveoli. The exudation of a liquid component in the alveoli was clearly seen (Fig. 1). In the cases of pulmonary edema after an operation for cardiopulmonary diseases, a congestion of the pulmonary vascular system and hemorrhage into the the alveoli were remarkable. This was particularly true in the cases where there was pulmonary hypertension before the operation. In such cases the fibrosis of the blood vessels was seen in addition to the above mentioned hemorrhage and the congestion. 


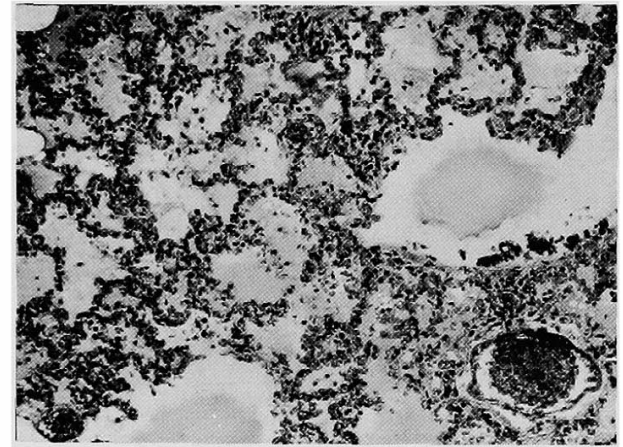

Fig. 1. Congestion, floating of red cells and exudation of liquid component in the alveoli in a case of pulmonary edema after the brain operation (bilateral frontal lobotomies), Case 7, F. M. 4 y. 우, H-E, $\times 90$.

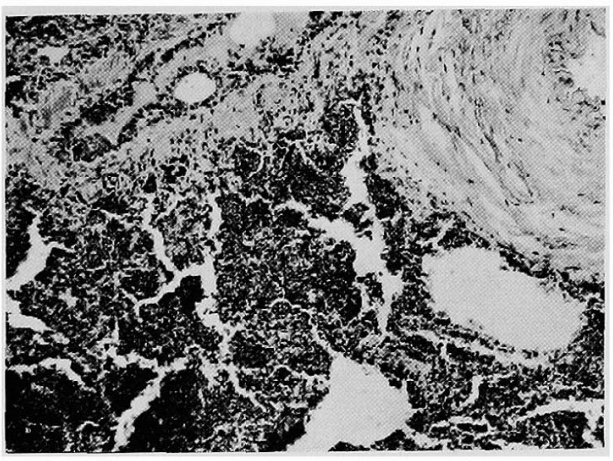

Fig. 2. Remarkable hemorrhage into the alveoli with fibrous thickening of the vessel wall in a case of pulmonary edema after the cardiac operation (congenital cardio-vascular malformation; truncus arteriosus), Case 22,

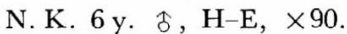

Though the exudation of liquid component into the alveoli was also seen, its degree was much less than that in cases of brain lesions (Fig. 2). In the cases of pulmonary edema after an operation of abdominal diseases accompanying hypoalbuminemia, anemia and hepatic or renal disturbance, the congestion was not remarkable, but a high degree of exudation of liquid component into the alveoli was observed (Fig. 3).

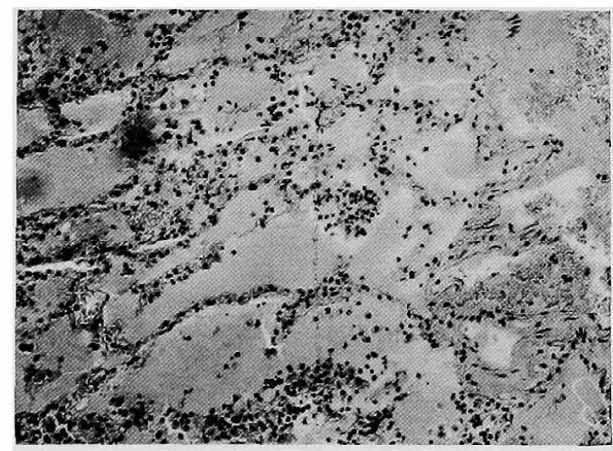

Fig. 3. High degree of exudation of liquid component into the alveoli without congestion in a case of pulmonary edema after abdominal operation (gastric cancer with metabolic disorder), Case 39, S. O. 55 y. 우, H-E, $\times 90$.

In order to determine the incidence of these 3 types, a calculation was, made about the ratios of the numbers of major brain, cardiopulmonary and abdominal operations to the numbers of occurrence of pulmonary edema. These were $12 \%, 3 \%$ and $1 \%$, respectively (Table III). It is worthy of note that the incidence of the postoperative pulmonary edem in brain 
surgery is significantly higher than those in other types of operations.

Table III. Incidence of Postoperative Pulmonary Edema in Clinical Cases

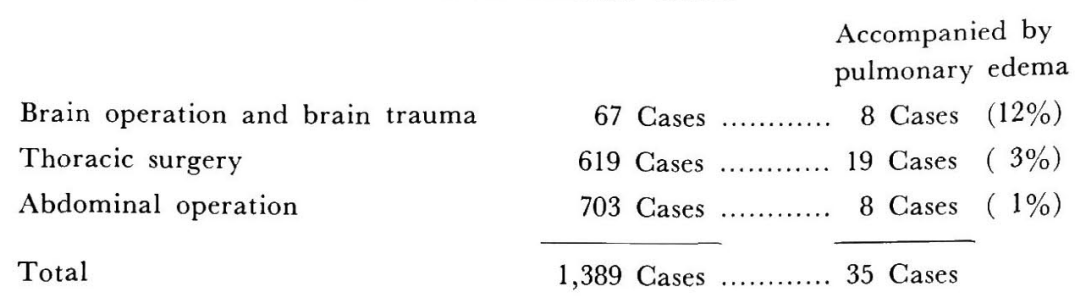

III. Innervation of the Pulmonary Vessels

For the purpose to clarify the relationship between the nervous system and the development of the pulmonary edema, an investigation about the innervation of the pulmonary vessels was performed.

From this investigation 2 terminals were found by silver impregnation: myelinated afferent one and nonmyelinated efferent one around capillaries of the pulmonary vessels (Fig. 4). The diameter of the nerve fibers of the

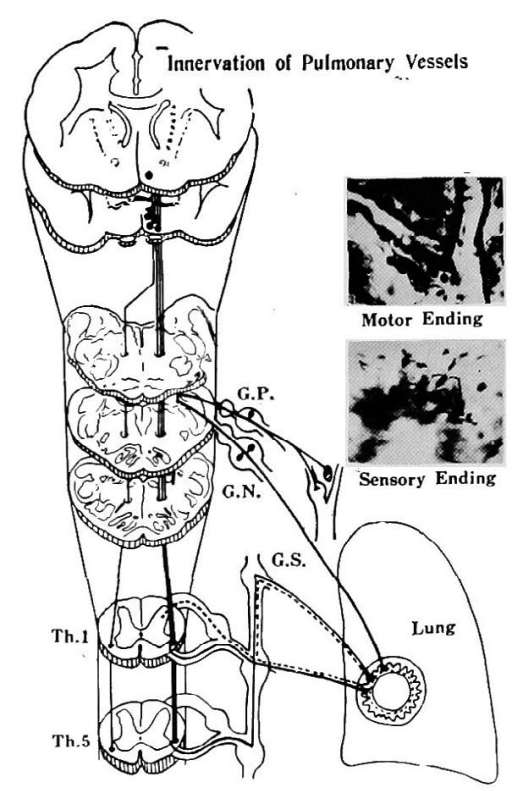

Fig. 4. Innervation of pulmonary vessels.

sensory ending varied from 4 to $8 \mu$. The ascending afferent pathway from this ending was traced by picking up the evoked potential in the medulla to the stimulation of the pulmonary vessels. The fibers were assumed to ascend mostly in the vagus nerve and attain to the infrasolitary nucleus and the ventral portion of the lateral nuclei of the solitary tract. The 
diameter of the fibers was calculated as 6 to $8 \mu$ from the conduction velocity. It was considered that there might be afferent pathways other than the one ascending along the vagus nerve, and they might run in the sympathetic or sinus nerve, since a slight elevation of the pulmonary arterial pressure was seen subsequent to an adequate stimulation of the pulmonary hilum even after bilateral cervical vagotomies and since the pulmonary arterial pressure was elevated during the stimulation after a complete section of the spinal cord at the level of $\mathrm{C}_{1}$. It was clarified from the decerebration experiments that the afferent pathway ascending the vagal nerve passed through the nuclei around the solitary tract to the midbrain.

Seeking the portion in the cerebrum and the brain stem at which a stimulation caused the selective elevation of pulmonary arterial pressure, it was found that an electrical stimulation of the nucleus preopticus principalis and nucleus preopticus magnocellularis of the preoptic area induced a characteristic elevation of pulmonary arterial pressure (Fig. 5).

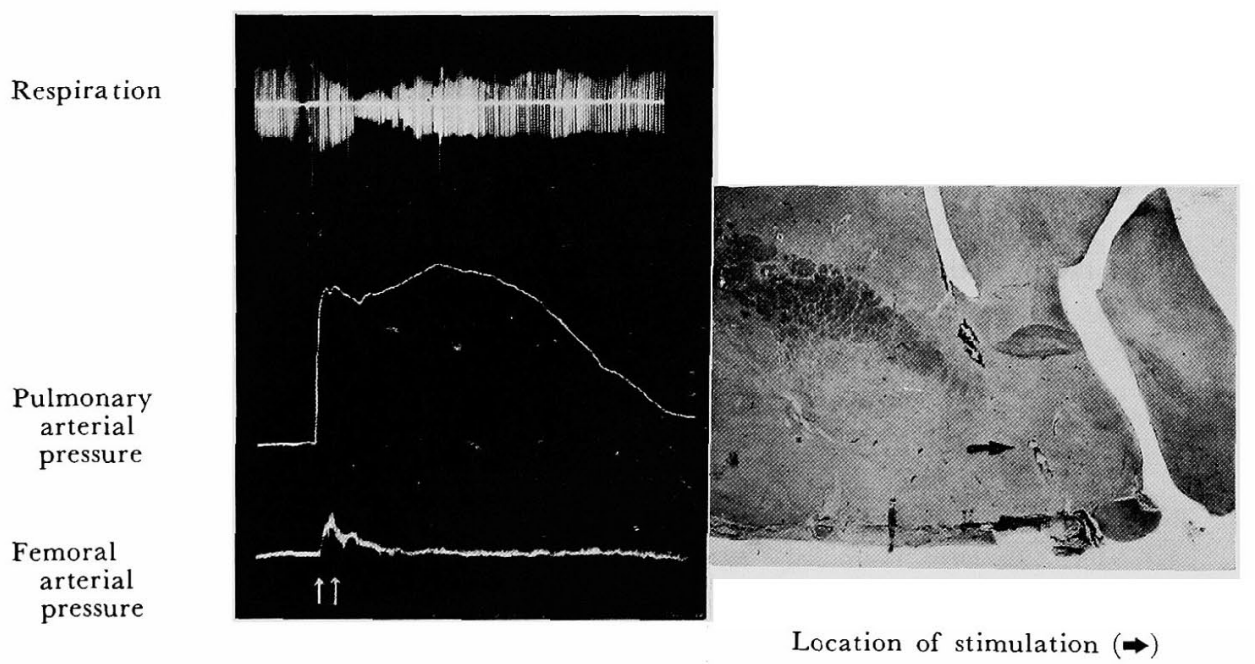

Fig. 5. Changes in pulmonary arterial pressure caused by stimulation of the preoptic area (N. preopticus principaris).

By the stimulation of other portions around these nuclei, namely the hypothalamus, the caudate nucleus and the internal capsule, there was no rise of pulmonary arterial pressure. The efferent pathway from these nuclei of preoptic areas passed the reticular formation ventral to the tegmentum at the level of the pons and passed through the ventral portion of the reticular formation at the level of the medulla, descending mostly ipsilaterally and partially contralaterally, passed through the bilateral anterolateral funiculi of the spinal cord and entering the sympathetic nerve from the spinal cord at the portion between $\mathrm{C}_{1}$ and $\mathrm{Th}_{5}$, distributed to the pulmonary vessels (Fig. 4 and 6). 
It could be concluded that there were both higher and lower centers on the reflex arc which consists of afferent and efferent

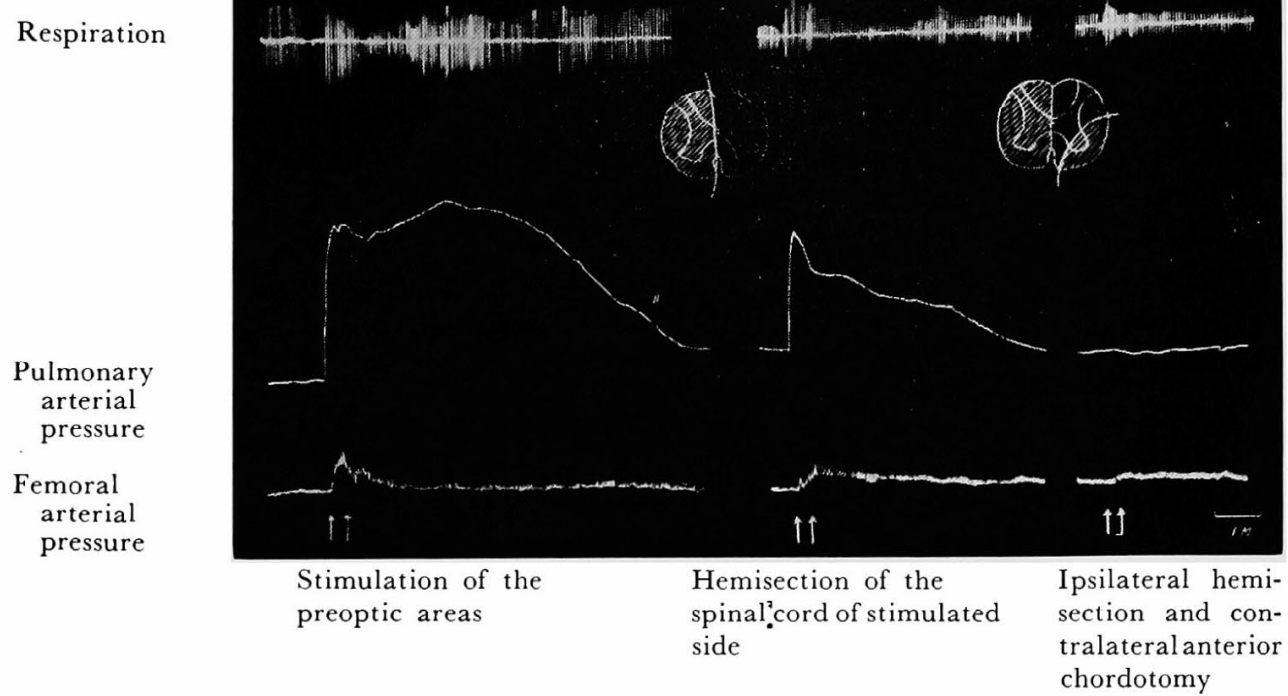

Fig. 6. Changes in pulmonary arterial pressure subsequent to stimulation of the preoptic areas and section of the spinal cord.

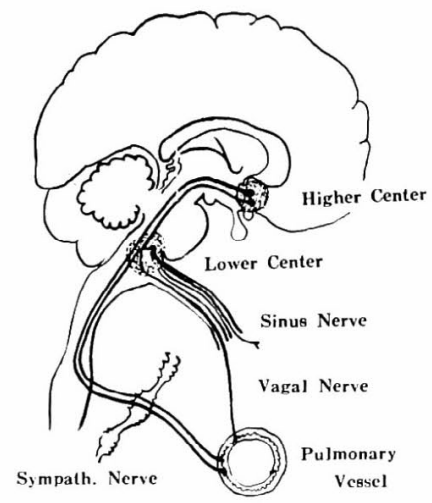

Fig. 7. Reflex centers of innervation of the pulmonary vessels clarified by section and stimulation experiments.

pathways of the pulmonary vascular innervation (Fig. 7). The higher center of the reflex arc where the afferent pathway ascends the vagal nerve was situated in the nuclei of the preoptic areas. The efferent pathway starting from this center passed through the pons, the medulla and the upper spinal cord and, entering the efferent sympathetic nerve, was distributed to the pulmonary vessels. On the other hand, the lower 
Table IV. Site of Attacks in Cases of Pulmonary Edema after Brain Operation and Brain Trauma

\begin{tabular}{|c|c|c|c|}
\hline & Case & Diseases & Operation \\
\hline \multirow{15}{*}{$\begin{array}{l}\text { 1st group; } \\
\text { relating to } \\
\text { preoptic area } \\
\text { and hypothal- } \\
\text { amus. }\end{array}$} & 3. T. О. 50 & Hypophyseal tumor & $\begin{array}{l}\text { Frontal craniotomy, } \\
\text { exstirpation of tumor }\end{array}$ \\
\hline & 4. K. K. 18 & Malignant craniopharyngeoma & $\begin{array}{l}\text { Frontal craniotomy, } \\
\text { resection of tumor }\end{array}$ \\
\hline & 5. T. F. 53 & Basis fracture & \\
\hline & 6. T. D. 63 & $\begin{array}{l}\text { Hemorrhage of right lateral ven- } \\
\text { tricle and } 3 \text { rd ventricle basis }\end{array}$ & $\begin{array}{l}\text { Bilateral frontal } \\
\text { lobectomies }\end{array}$ \\
\hline & 7. F. M. 4 & Traumatic aphasia & \\
\hline & 9. K. S. 48 & $\begin{array}{l}\text { Contusion of left frontal and } \\
\text { temporal lobes }\end{array}$ & \\
\hline & 10. K. M. 42 & $\begin{array}{l}\text { Subarachnoidal and intraven- } \\
\text { tricular bleeding }\end{array}$ & \\
\hline & 12. T. T. 19 & $\begin{array}{l}\text { Contusion of right frontal and } \\
\text { temporal lobes }\end{array}$ & \\
\hline & 13. M. S. 28 & $\begin{array}{l}\text { Contusion of inferior part of left } \\
\text { frontal lobe and olfactory region }\end{array}$ & \\
\hline & 14. J.Y. 43 & $\begin{array}{l}\text { Contusion of left frontal and } \\
\text { temporal lobes }\end{array}$ & \\
\hline & 15. M. M. 37 & $\begin{array}{l}\text { Contusion of left frontal and } \\
\text { temporal lobes }\end{array}$ & \\
\hline & 16. H. M. 32 & $\begin{array}{l}\text { Hemorrhage of inferior part of } \\
\text { right frontal lobe and in ventricle }\end{array}$ & \\
\hline & 17. H. M. 69 & $\begin{array}{l}\text { Contusion of left frontal and } \\
\text { temporal lobes }\end{array}$ & \\
\hline & 18. K.S. 35 & $\begin{array}{l}\text { Pressures of right frontal and } \\
\text { temporal lobes by the hematoma }\end{array}$ & \\
\hline & 19. W. K. 35 & $\begin{array}{l}\text { Contusion of left hemisphere, } \\
\text { especially frontal half }\end{array}$ & \\
\hline \multirow{4}{*}{$\begin{array}{l}\text { 2nd Group; } \\
\text { relating to } \\
\text { pons and } \\
\text { medulla. }\end{array}$} & 1. F.Y. 16 & Tumor in lateral ventricle & Craniotomy \\
\hline & 2. K. H. 48 & Cerebellar pontine angle tumor & $\begin{array}{l}\text { Suboccipital cranio- } \\
\text { tomy, resection of } \\
\text { tumor }\end{array}$ \\
\hline & 8. M. O. 4 & (Bulbar palsy symptom) & Lobotomy \\
\hline & 11. Y. M. 56 & $\begin{array}{l}\text { Hematoma of frontal portion, } \\
\text { bleeding of cerebral peduncle and } \\
\text { pons }\end{array}$ & \\
\hline
\end{tabular}


center of the reflex arc where the afferent pathway ascends the sympathetic nerve or sinus nerve was situated in the medulla and from this the efferent pathway turned immediately into the efferent sympathetic fibers.

We have also studied a participation of the nervous factor in the development of the pulmonary edema in our clinical cases (Table IV). Among 46 clinical cases, 19 cases have developed the edema aftcr a brain operation or brain trauma. The sites of lesions in these cases have been thoroughly investigated. There have been 8 cases (12\%) of the postoperative pulmonary edema among 67 cases of brain operation during past 5 years. Five cases of them were those developed the edema after the operations of malignant craniopharyngioma, hypophyseal adenoma with Gushing's syndrome and brain stem lesion and after frontal lobotomy. These foci were adjacent to the preoptic areas and the hypothalamus. The operations were performed through frontal craniotomy, approaching

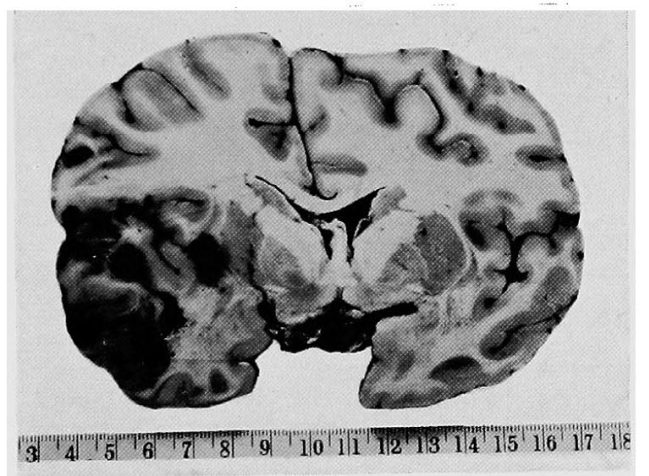

Fig. 8. Location of foci of a case of brain trauma accompanied by pulmonary edema. There is seen the contusion extending from the temporal lobe to the striate body (case No. 12. T. T. $19 \mathrm{y}$. $)$.

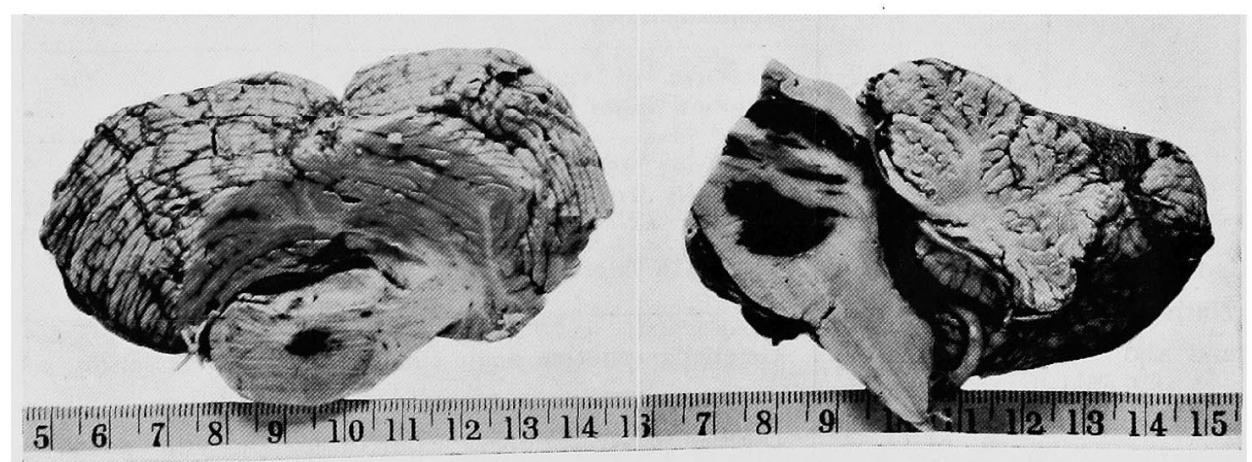

Fig. 9. Location of foci of a case of brain trauma accompanied by pulmonary edema. There is seen hemorrhagic focus in the pons (case No. 11, Y. M. $56 \mathrm{y}$. 우). 
to the optic chiasma by lifting orbital side of the frontal lobe. In the remaining 3 cases, the pulmonary edema occurred after the operations for cerebellar tumor, pontine tumor and lateral ventricular tumor having relations to the pons and the medulla. These operations were carried out mostly by suboccipital craniotomy. Among the 11 cases died of brain trauma accompanied by the pulmonary edema, 10 had the lesions in the vicinity of the preoptic areas, and one in the medulla (Fig. 8 and 9).

Summarizing these findings, it was found that the foci or the operative attacks in some cases had a close relation to the higher center in the
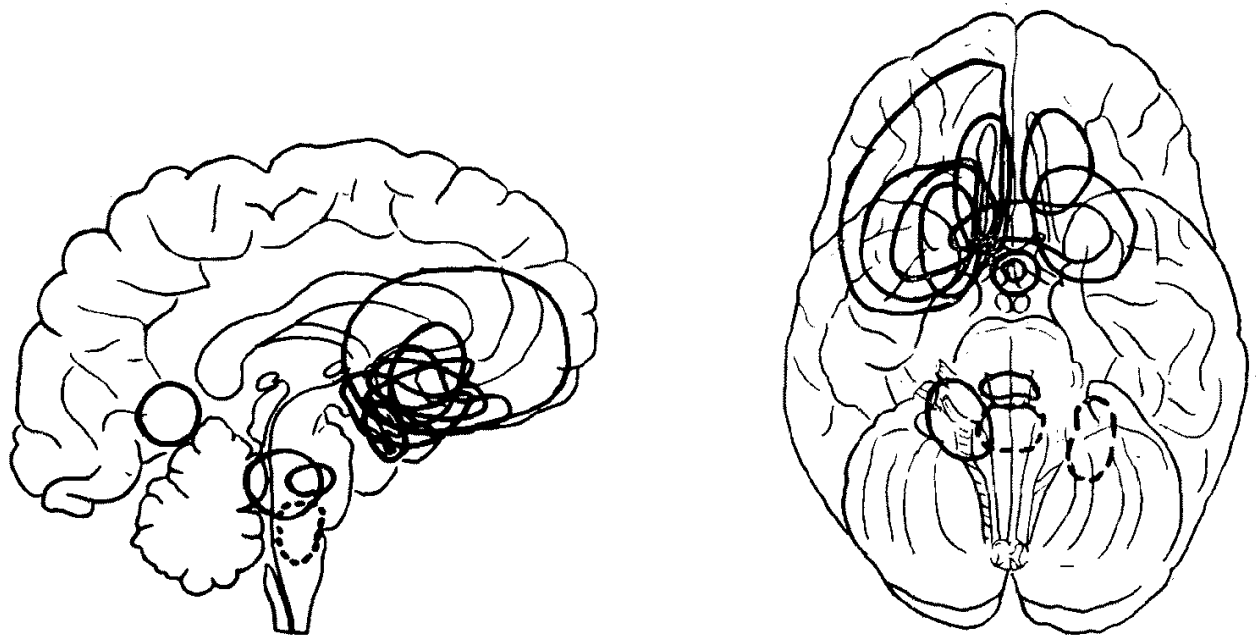

Fig. 10. Location of foci of cases of the central nervous diseases accompanied by pulmonary edema.

preoptic areas which had been experimentally disclosed, and the foci or the operative attacks in another group had close relation to the lower center in the medulla (Fig. 10).

IV. Pathological Physiology of Experimentally Produced Pulmonary Edema

The pulmonary edema could be produced, bringing about changes in the pulmonary circulation, by destroying any of the courses of the pulmonary vascular innervation.

When the bilateral preoptic areas, which are regarded as the higher center of the pulmonary vascular innervation, were completely destroyed by an electrocoagulation, the pulmonary edema occurred frequently (Fig. 11). In order to produce this type of the pulmonary edema, it was necessary to destroy the both sides of the preoptic areas completely. Destruction of one side of the preoptic areas did not cause the pulmonary edema. Furthermore, destruction of other portions of the brain such as the hypothalamus and the cerebral cortex did not produce any pulmonary edema. 


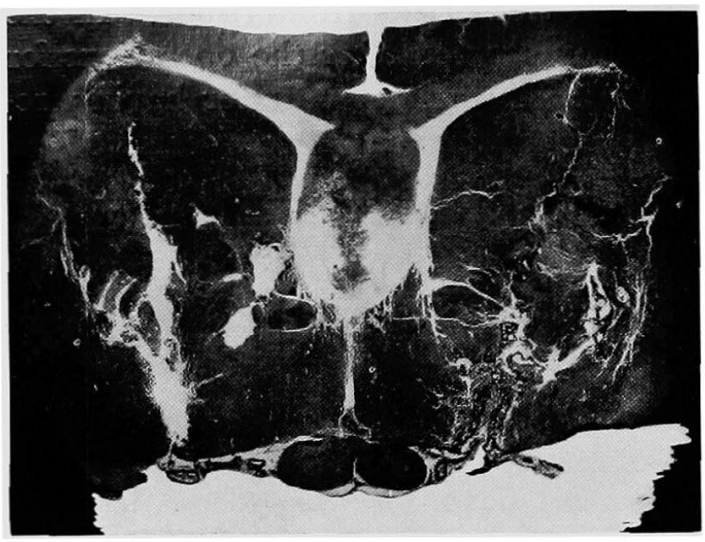

(a)

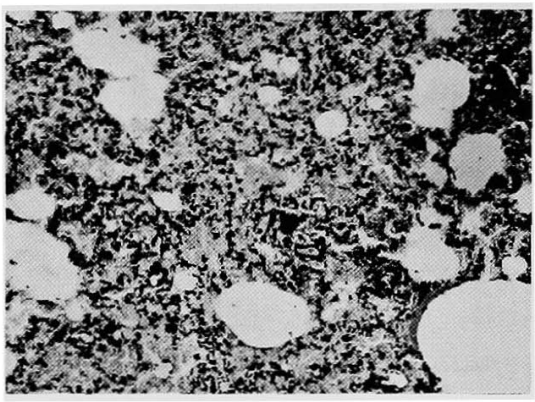

(b)

Fig. 11. Destroyed portion of the bilateral preoptic areas to produce pulmonary edema and histological figures of the lung of pulmonary edema caused by the lesions.

(a) Frontal section slightly magnified.

(b) Notice the exudation of fluid into the alveoli as well as the bronchioli and the hemorrhage in interstitium $(\times 90)$.

When the bilateral preoptic areas were destroyed, the animal could hardly survive for a long time and died 6-7 hours after the operation. The edema occurring in such a case was mostly involved in the lung. Moreover, histology of thus experimentally produced pulmonary edema was exactly the same as that of the clinical pulmonary edema occurring after brain operation or brain trauma (Fig. 10 and 11).

In the cases of experimentally produced pulmonary edema by complete destruction of the bilateral preoptic areas, various pathophysiological responses have been observed in detail: Respiration was markedly suppressed. Oxygen consumption and arterial blood oxygen saturation became lower. A gradual fall in arterial pressure with decreased cardiac output was seen. Pulmonary arterial pressure was elevated and reached to 350-450 mm. $\mathrm{H}_{2} \mathrm{O}$ (Fig. 12). This marked elevation of pulmonary arterial pressure was the characteristic phenomenon in the bilateral preoptic lesions. The destruction of other portions of the brain stem or the unilateral preoptic lesion did not raise pulmonary arterial pressure. Pulmonary vascular resistance increased considerably, pulmonary circulation time became prolonged, and pulmonary blood volume also seemed to be increased (Fig. 12). Hepatic blood flow as well as renal blood flow decreased remarkably, and urine excretion became extremely low (Fig. 13). Serum protein and colloidal osmotic pressure of plasma did not show any remarkable changes. The increase in the extracellular fluids was slight, but the fluids in the tissue stroma showed a remarkable increase due to a decreased circulating 

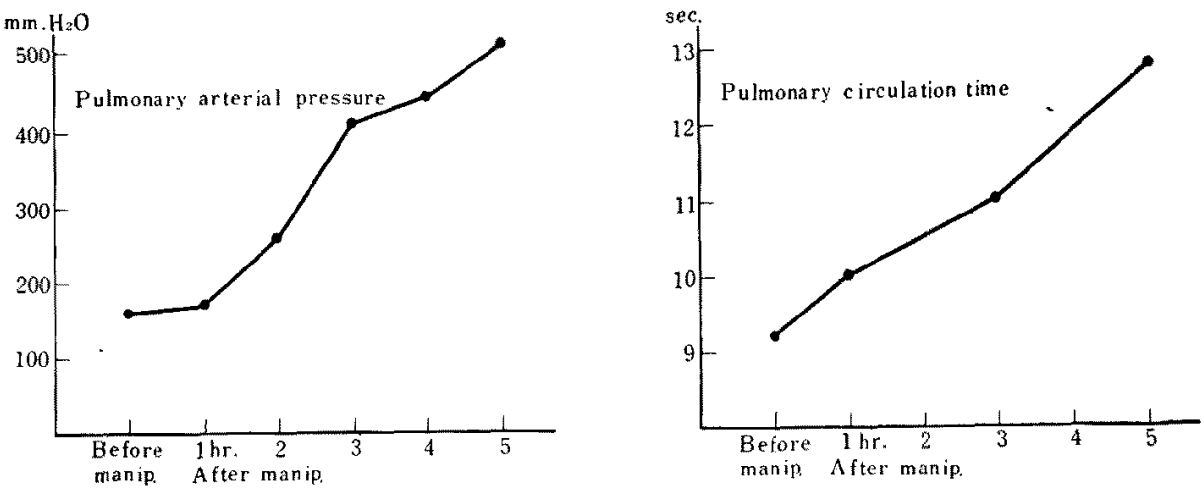

Fig. 12. Changes in pulmonary circulation in the process of pulmonary edema produced by bilateral preoptic lesions.
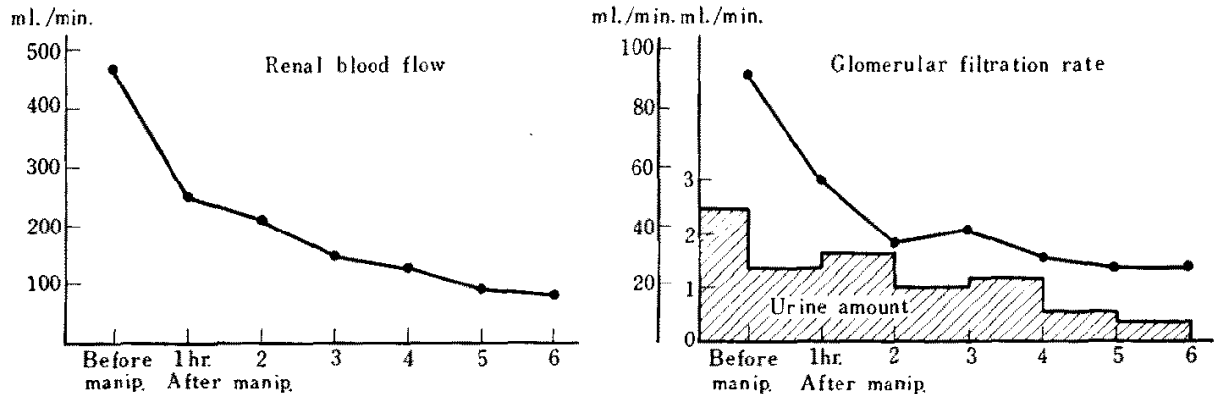

Fig. 13. Changes in renal circulation in the process of pulmonary edema produced by bilateral preoptic lesions.

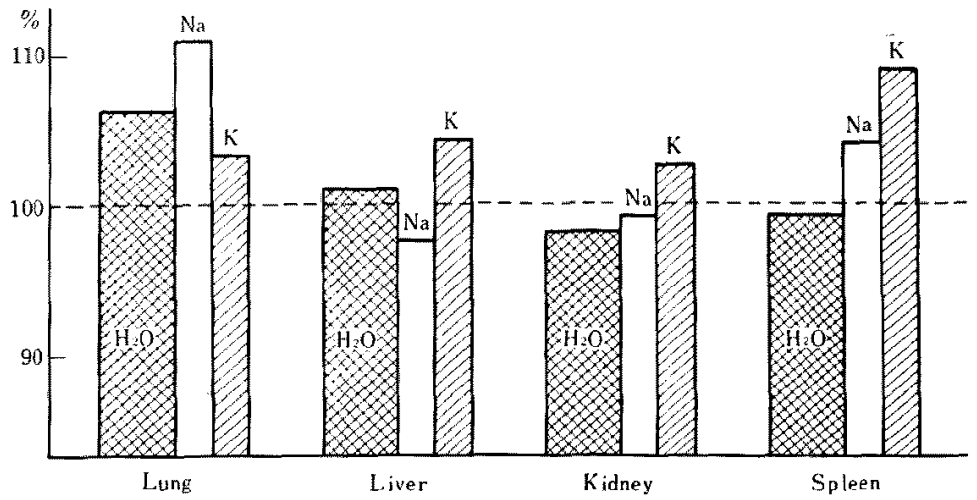

Fig. 14. Tissue water volume and electrolytes of various organs in the process of pulmonary edema produced by preoptic lesions, showing the increase and the decrease in pulmonary edena with percentage by making normal value $100 \%$. 
blood volume. As to the changes of electrolytes in plasma and tissues, the retention of sodium in plasma and the lung was remarkable. Tissue water was also increased in the lung (Fig. 14). The pulmonary dilution curve which was made by an incorporation of $\mathrm{Na}^{24}$ and $\mathrm{P}^{32}$ labelled red cells showed transcapillary water exchange and the dynamics of intrapulmonary water shift clearly (Fig. 15). Both the exudation of water into the lung
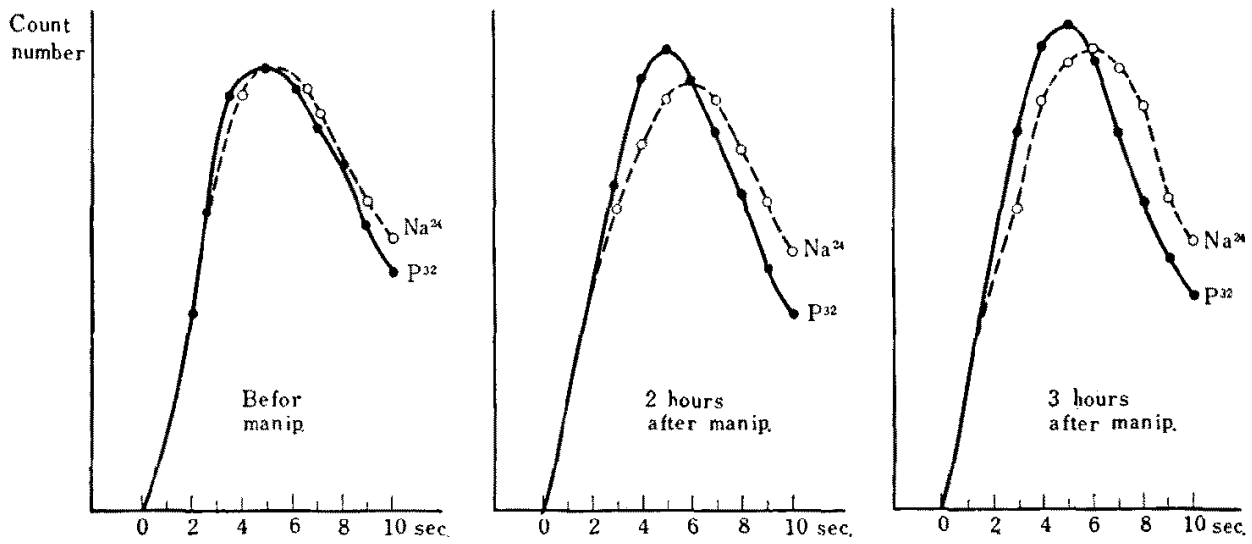

Fig. 15. Dilution curve of the lung by means of $\mathrm{Na}^{24}$ and $\mathrm{p}^{32}$ labelled erythrocytes in the progress of pulmonary edema produced by preoptic lesions. The both curves make approximately same course before operation. After preoptic lesions, $\mathrm{Na}^{24}$ curve shifts to the right showing the increase in water exchange. $\mathrm{P}^{\mathrm{y} 2}$ counts over $\mathrm{Na}^{24}$ counts implies that transudation of water surpasses reabsorption in the pulmonary capillaries.

and the absorption from the lung were going on rapidly and vigorously in the early stage, while in the late stage the transudation of water overwhelmed the reabsorption of water resulting in a prominent pulmonary

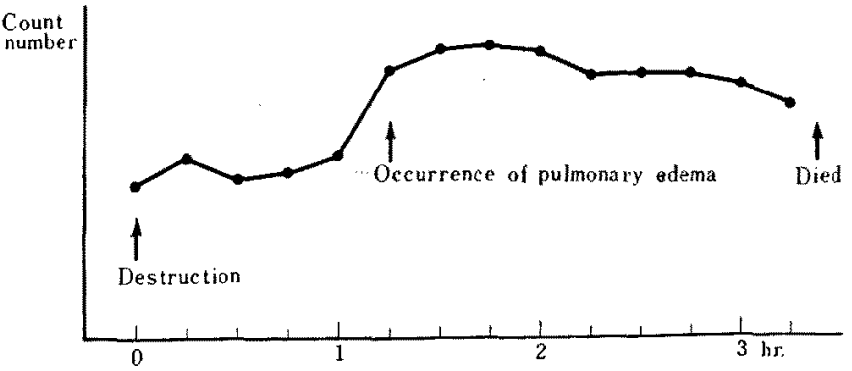

Fig. 16. Appearance of $\mathrm{Na}^{24}$ in the blood after injection of $\mathrm{Na}^{24}$ into the bronchi, in the progress of pulmonary edema produced by preoptic lesions. In the progress of pulmonary edema, the count number increases.

In the advanced stage of pulmonary edema the count number is refrained from increase, the curve becomes flat and the count number decreases gradually. 
edema. When the distribution of water to various tissues was traced by Aviado's method, the muscle reserved much water in the case of simple transfusion, while in the case of bilateral preoptic lesions, water was accumulated into the lungs selectively, producing the pulmonary edema (Fig. 16). When $\mathrm{Na}^{24}$ was injected into the alveoli, the absorption curve of blood rose in the early stage of pulmonary edema, but at the maximal stage the absorption was suppressed producing a flat curve. The pulmonary lymphatic flow increased from time to time, but eventually it began to decrease. The reticulate fiber of the alveolar wall showed some swelling,

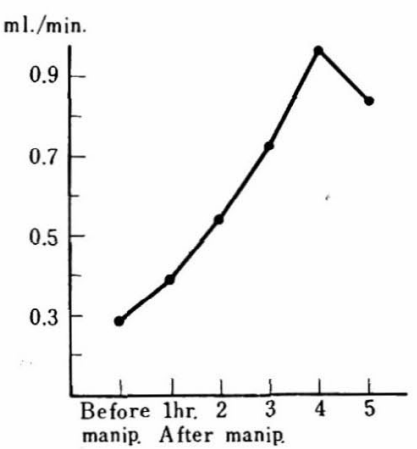

(a)

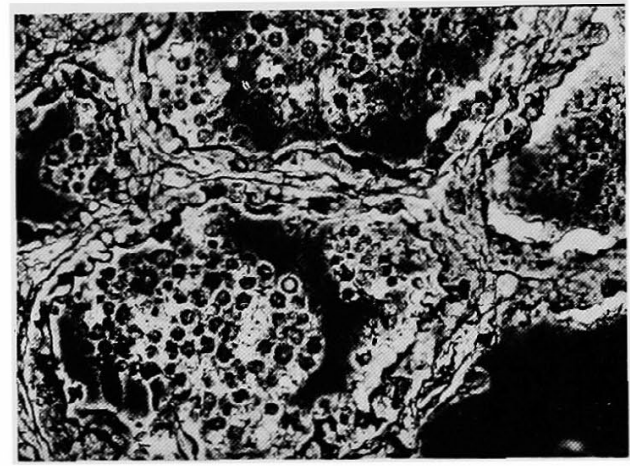

(b)

Fig. 17. Changes in pulmonary lymph flow and reticular fiber of the alveolar wall in the process of pulmonary edema produced by preoptic lesions.

(a) Pulmonary lymph flow.

(b) The reticular fiber of the alveolar wall shows swelling, broadening and breaking $(\times 180)$.

broadening, and breaking which nicely represent the changes in the pulmonary lymphatic flow (Fig. 17). 17-Hydroxycorticosteroid in blood, 17-ketosteroid in urine and antidiuretic substance in blood increased from the beginning (Fig. 18). It is worthy of note that these hormonal changes
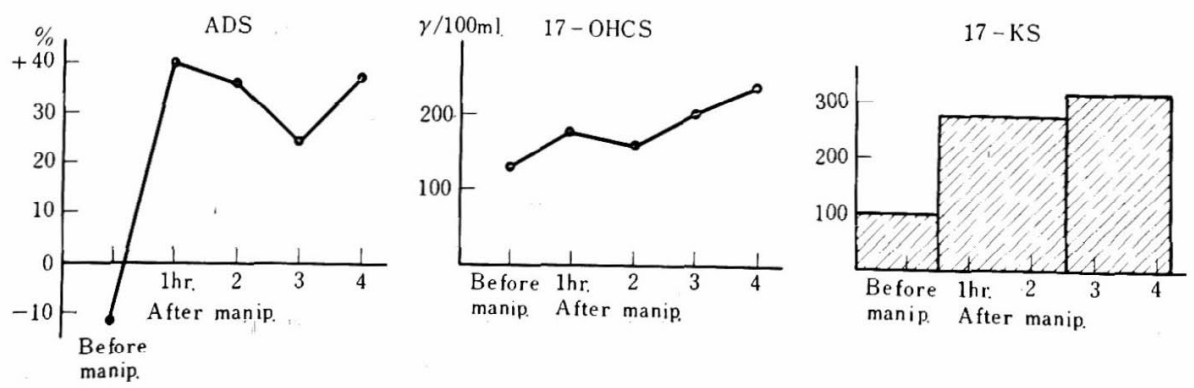

Fig. 18. Endocrine changes in the process of pulmonary edema produced by preoptic lesions (A. D. S. : Anti-diuretic substance). 
occurred immediately after the production of the bilateral preoptic lesions. This might indicate that the damage of the preoptic areas would influence directly upon the hormonal regulation, inducing the hormonal unbalance. VDM decreased in the liver and increased in the blood. The activity of
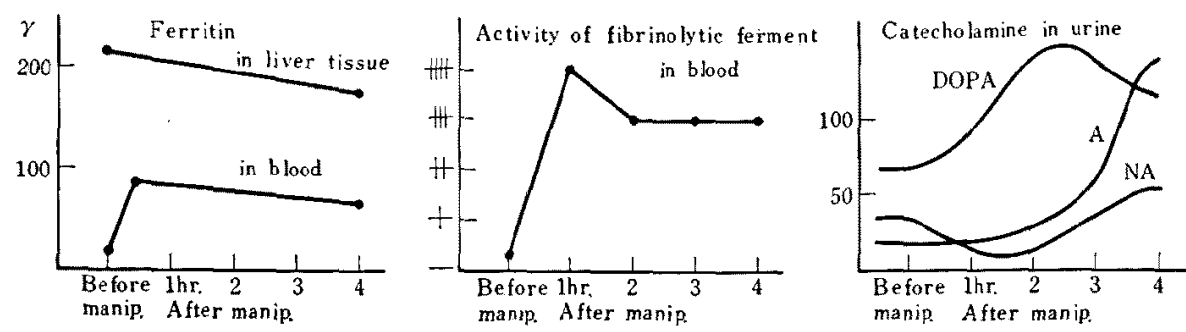

Fig. 19. Changes in ferritin, fibrinolytic ferment and catecholamine in the process of pulmonary edema produced by preoptic lesions.

fibrinolytic enzyme became strong, histamine of the lung tissue and free catecholamine in urine increased markedly from the beginning (Fig. 19). The permeability of the pulmonary capillaries became increased with the lapse of time as seen in passing of the trypan blue through the pulmonary artery. Phosphatase activity, 5-nucleotidase activity, RNA metabolism, lipid metabolism and polysaccharide metabolism in the tissues of the lung and the liver became vigorous in the early stage of development of pulmonary edema, but, as time went on they became unbalanced and weakened (Fig. 20).

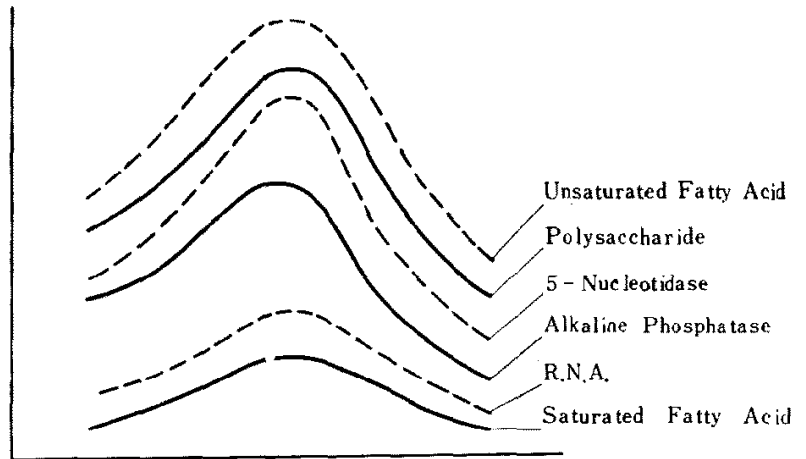

Fig. 20. Changes in histochemistry in the process of pulmonary edema produced by preoptic lesions.

When the pulmonary edema was induced by the stimulation on the sympathetic nerve which is a part of the reflex arc of the pulmonary vascular innervation, there were little changes in plasma colloidal osmotic pressure, urinary volume, water and electrolytes in both urine and tissues 
and the permeability of the pulmonary vessels. However, there was an elevation of pulmonary arterial pressure during the stimulation.

When the vagus nerve was severed at the cervical region and its proximal end was stimulated, pulmonary edema appeared. In this case, pulmonary arterial pressure became elevated during the stimulation and plasma colloidal osmotic pressure was lowered. Water and sodium in the lung tissue were increased slightly. There was little change in the permeability of the pulmonary vessels.

For the purpose of comparing the pathophysiological characteristic of the pulmonary edema of cerebral origin with that of the other type, we have produced the cxperimental pulmonary edema corresponding to the second group of clinical postoperative pulmonary edema; that occurring after an operation of the cases with cardiopulmonary diseases accompanying some pulmonary circulatory disturbances. This type of the pulmonary edema was reproduced by the pneumonectomy in combination with low oxygen respiration, inspiratory resistance, and massive intravenous infusion of the saline solution. ${ }^{19}$ Pathophysiology has been found to be as follows: there were observed a decreased oxygen saturation of the peripheral arterial blood, lowered peripheral arterial pressure and a gradual fall of cardiac output. Following a massive intravenous infusion of the saline, a transient increase in the circulating blood volume occurred, but disappeared gradually as the fluids in the tissue stroma became increased. The pulmonary lymphatic flow increased. Pulmonary arterial pressure rose immediately after an operation and remained high. Colloidal osmotic pressure of plasma became lowered markedly (Fig. 21). Renal circulation
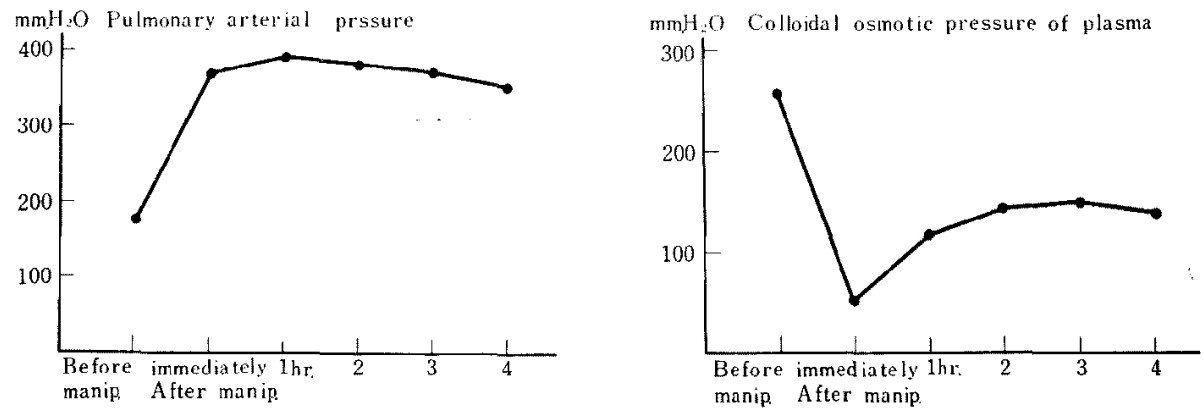

Fig. 21. Changes in pulmonary arterial pressure and colloidal osmotic pressure in the process of pulmonary edema produced by hypoxia, inspiratory resistance and rapid saline infusion after lobectomy.

as well as renal function in the early stage were so good that the infused fluid was completely excreted, but in the late stage the excretion of the fluid became retarded resulting in the retention of both water and electrolytes in the body (Fig. 22). The amount of the tissue fluids became increased in 

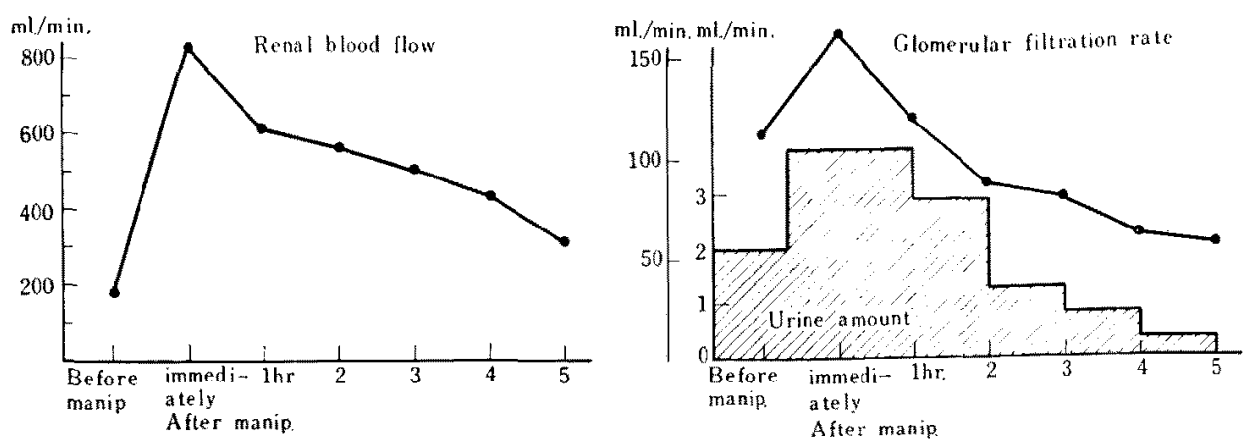

Fig. 22. Changes in renal circulation in the process of pulmonary edema produced by hypoxia, inspiratory resistance and rapid saline infusion after lobectomy.

all the organs, particularly in the lung. There were some increase in the excretion of antidiuretic substance and of adrenocortical hormones, and an increase of ferritin in blood (Fig. 23). There was an increase in the
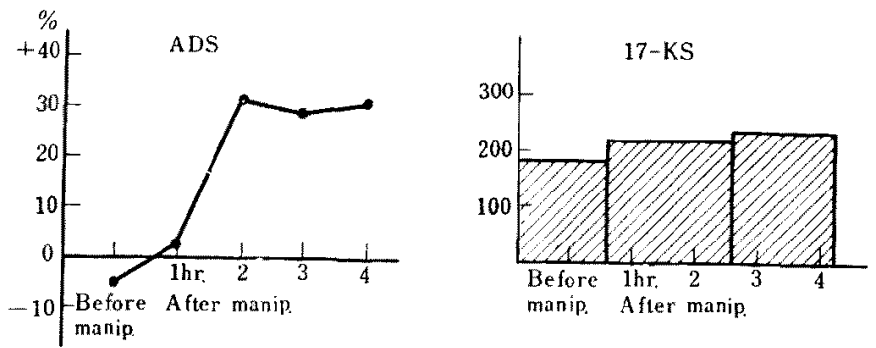

Fig. 23. Endocrine changes in the process of pulmonary edema produced by hypoxia, inspiratory resistance and rapid saline infusion after lobectomy.

activity of fibrinolytic ferment in blood. These changes were not remarkable immediately after the procedures of producing pulmonary edema, but they progressed in intensity gradually in the late stage.

In addition, we were also able to producc another type of the experimental pulmonary edema corresponding to the third group of clinical postoperative pulmonary edema; that occurring after an abdominal operation of cases with metabolic disorder such as hypoalbuminemia, anemia and hepatic or renal disturbance. It was produced by an injection of ANTU. ${ }^{19}$, In this condition, the permeability of the pulmonary vessels became increased extraordinarily, and there were little changes in pulmonary circulation, electrolytes in blood and of colloidal osmotic pressure in plasma. The renal blood flow as well as urinary output were decreased. 


\section{Discussion}

From the results of clinical and experimental examinations in the present study, the pathophysiology and the genesis of the clinical postoperative pulmonary edema are assumed as follows.

In case of an acute pulmonary edema occurring following an operation or a trauma of the brain, the operation or the trauma is directly (primarily) responsible for the rise of pulmonary arterial pressure, ${ }^{28,301-32}$ ) the prolongation of pulmonary circulation time and the increase in the permeability of the pulmonary capillaries. This pulmonary hypertension is so high that it overcomes the colloidal osmotic pressure to push the fluids out of the vascular bed into the lung tissue. ${ }^{381-855}$ This factor would play a major rôle in the production of the pulmonary edema. In addition to causing the pulmonary hypertension, the operation or the trauma directly (primarily) causes the changes in renal $^{28}$ ) or hepatic circulation and in endocrine regulation, inducing anuria and electrolytes disturbance. $\left.{ }^{28}\right)$ The combination of these accelerates the production of exclusive pulmonary edema. Bilateral preoptic lesions cause a severe respiratory depression accompanied by a lowering of oxygen saturation in arterial blood and respiratory acidosis. A similar depression might be seen not only in the bilateral preoptic lesions, but also in an unilateral preoptic lesion or in a thalamic lesion on both sides of the third ventricle. However, either unilateral preoptic lesion or thalamic lesion would not produce any pulmonary hypertension or pulmonary edema. Therefore, the pulmonary hypertension and the pulmonary edema following an operation or a trauma to the brain can not be regarded as a result from a simple respiratory depression alone, ${ }^{10,26,227}$ but should be regarded as a direct result from the damage of the higher center of the reflex arc, though we do not ignorc a fact that the respiratory depression will facilitate the production of the pulmonary edema. ${ }^{19 /, 36 /-39)}$

The pulmonary edema occurring after an operation for cardiopulmonary diseases accompanied by pulmonary circulatory disturbances is often caused by a misuse of blood transfusion during and after the operation. In such a case, a continual rise of pulmonary arterial pressure and a marked lowering of colloidal osmotic pressure of plasma are the predominating factors causing the pulmonary edema. ${ }^{40)-42}$ Once the pulmonary edema is induced, it becomes a stress resulting indirectly (secondarily) in a renal circulatory failure, a hormonal disturbance, an increase in the permeability of the pulmonary capillaries and the further promotions of the pulmonary edema. The renal factor is one of the important factors in the occurrence of the pulmonary edema. There is a different behavior of the kindey between the case of postoperative pulmonary edema caused by lesion of the central nervous system and the case of postoperative pulmonary edema 
of cardiopulmonary diseases. In the former, the kidney acts dynamically and actively to retain water and electrolytes in the body, while in the latter the kidney is not able to deal with rapidly infused water resulting in a passive retention in the body. ${ }^{28,}, 42$ )

The pulmonary edema occurring after an operation of abdominal diseases accompanied with some metabolic disorders such as hypoproteinemia, anemia, and hepatic or renal disturbance is characteristically caused by a tremendous increase in the permeability of the pulmonary capillaries. ${ }^{29}, 437,441$

As far as the prognosis of the postoperative pulmonary edema is concerned, one can find that some cases of postoperative pulmonary edema respond to the treatment nicely and others progress in its severity in spite of every effort of the treatments. One should consider a fact that there are many cases of pulmonary edema which may not be diagnosed clinically because of a lack of clinical manifestations and in these cases the patients recover from transient edema without any specific treatment. Only the cases associated with severe clinical manifestations of the pulmonary edema may receive the therapy and some may recover from it and some may not. In all types of pulmonary edema, 2 phenomena will develop simultaneously: the transudation of the fluids from the vessel into the alveoli or into the stroma and the reabsorption of the fluids through the lymphatic and the vascular vessels. In the early stage of the pulmonary edema, both phenomena become evident. However, in the late stage the transudation surpasses the reabsorption, resulting in manifestation of the scvere pulmonary edema. As long as the reabsorption exists, the pulmonary edema may be reversible. If the pulmonary edema, however, progresses in its severity and continues for some period of time, several factors eventually influence upon the reabsorption, resulting in its marked decrease or disappearance, and lead into an irreversible pulmonary edema.

\section{Summary}

(1) By investigating many autopsy cases, it was found that the incidence of combination of the pulmonary edema was high in the cases with central nervous system diseases, particularly in the cases having localized foci in the vicinity of the internal capsule, the lentiform nucleus and the third ventricle.

(2) From the histological viewpoint, an attempt was made to classify the clinical cases of postoperative acute pulmonary edema into 3 groups: (1) that occurring after a brain operation or brain trauma, (2) that occurring after a cardiopulmonary operation of cases with pulmonary circulatory disturbances, (3) that occurring after an abdominal operation of cases with metabolic disorders. It is worthy of note that the incidence of the 
postoperative pulmonary edema was significantly high after brain surgery.

(3) In the examination of the pulmonary vascular innervation, the reflex pathway has been clarified and the 2 centers were assumed to be in the reflex arc of the innervation of the pulmonary vessels. The higher center of the reflex arc ascending through the vagus nerve was in the nuclei of the preoptic areas, while the lower center of the reflex arc ascending through the sympathetic or sinus nerve was in the medulla. The authors have also confirmed that the site of cerebral damage in the clinical cascs of pulmonary edema, occurring after a brain operation or a brain trauma, had a close relation to either the higher or the lower center of the pulmonary vascular innervation or the both.

(4) The authors have succeeded in the experimental production of the characteristic pulmonary edema of cerebral origin by a complete destruction of the bilateral preoptic areas. Pathophysiology concerning the experimentally produced pulmonary edema has been studied in detail.

(5) Based on the results of both clinical and experimental studies, the pathogenesis of the clinical pulmonary edema occurring after a brain operation or a brain trauma was assumed to be as follows. The operation or trauma was directly responsible for the development of pulmonary hypertension, the prolongation of pulmonary circulation time, and the increase in the permeability of the pulmonary capillaries. At the same time, the operation or the trauma directly caused the changes in renal or hepatic circulation and endocrine regulation, inducing anuria, disturbance of water and electrolytes balances. The combination of these factors accelerated a selective pulmonary edema of an acute type.

(Published in Nippon-Geka-Gakkai-Zasshi (J.J.S.S.) 61: 897, 1960, in Japanese)

\section{REFERENCES}

1. Moutier: Presse méd. 26: 108, 1918. (by Campbell, G.S. and Visscher, M. B. : Am. J. Physiol, 157 : 130, 1949.)

2. Hess, L.: Wien Med. Wschr. $84: 285,1934$.

3. Manuza and Paolo: Riv. Pat. Nerv. 45: 429, 1935. (Kongress-zentralblatt f. d. ges. inn. Med. u. Grenzgebiete 83 : 204, 1936.)

4. Weisman, S. J. Surg. 6: 722, 1939.

5. Ueda, H., Yabe, T. and Shimano, K.: Shindan-to-Chiryō (The Diagnosis and Treatment) 42: 417, 1954 (In Japanese).

6. Ohtani, K.: Niigata-Igakukai-Zasshi (Niigata Med. J.) 65: 742, 1951 (In Japanese).

7. Paine, R., Smith, J. R., and Howard, F. A.: J.A. M. A. 149: 643, 1952.

8. Altschule, M. D.: Physiology in Diseases of the Heart and Lungs, Harvard University Press, Cambridge, Massachusetts, p. 312, 1954. 
9. Koikegami, H., Fuse, H., Kido, T., and Kimoto, A.: Nō-to-Shinkei (Brain and Nerve) 4: 238, 1952 (In Japanese).

10. Gamble, J. E. and Patton, H. D. : Am. J. Physiol. 172: 623, 1953.

11. Koenig, H. and Koenig, R.: Am. J. Physiol. 158: 1, 1949.

12. Matsushita, T.: Nippon-Geka-Gakkai-Zasshi (J.J.S.S.) 42: 62, 1941 (In Japanese).

13. Haertig, E. W. and Wasserman, J. H.: J. Neurophysiol. 3: 293, 1940.

14. Glass, A.: Arch. f. Exp. Pathol. u. Pharmakol. 136: 88, 1929.

15. Cameron, G. R. and De, S. N.: J. Path. and Bact. 61: 375, 1949.

16. Campbell, G.S., Haddy, F.J., Adams, W. L., and Visscher, M. B.: Am. J. Physiol. 158: 96, 1949.

17. Campbell, G.S. and Visscher, M. B.: Am. J. Physiol. 157: 130, 1949.

18. Katsuki, S. and Fukutome, T.: Kokyū-to-Junkan (Respiration and Circulation) 3:658, 1955 (In Japanese).

19. Jordan, G. L.: Arch. Surg. 63: 191, 1951.

20. Campbell, G.S., Haddy, S.J., and Visscher, M. B.: Federation Proc. 8: 21, 1949.

21. Luisada, A. A. and Sarnoff, S. J.: Proc. Soc. Exper. Biol. and Med. 57: 279, 1944, Am. Heart J. 31: 270, 1946, ibid. 31: 282, 1946, ibid. 31: 293, 1946.

22. Farber, S.: J. Exper. Med. 66: 397, 1937, ibid. 66: 405, 1937.

23. Lorber, V.: J. Exper. Med. 77: 117, 1939.

24. Short, R. H. D.: J. Path. and Bact. 56 : 355, 1944.

25. Visscher, M. B., Haddy, F.J., and Stephens, G.: Parmakol. Review 8: 389, 1956.

26. Urabe, M., Segawa, Y., Kuzuba, S., Tsubokawa, T., and Izumi, K.: Kokyū-to-Junkan (Respiration and Circulation) 6 : 193, 1958 (In Japanese).

27. Urabe, M., Segawa, Y., Tsubokawa, T., and Izumi, K.: Neurologia medico-chirurgica $1: 16,1959$.

28. Izumi, K.: Nippon-Kyōbu-Geka-Gakkai-Zasshi (J.J. A. T. S.) 8: 844, 1960 (In Japanese).

29. Richter, C. P.: J. A. M. A. 129: 927, 1945.

30. Ueda, H.: Nihon-Rinshö 9: 1065, 1951 (In Japanese).

31. Sakaguchi, R.: Nippon-Junkanki-Gaku-Shi (Jap. Circulation J.) 20: 561, (In Japanese).

32. Ohta, Y.: Kokyū-to-Junkan (Respiration and Circulation) 1: 307, 1953 (In Japanese).

33. Schega, H. W: Langenbecks Arch. u. Dtsch. Z. Chir. 280: 479, 1955.

34. Cournand, A.: Circulation 2: 641, 1950.

35. Dexter, L., Dow, J. W., Haynes, F. W., Whittenberger, J. L., Ferris, B. G., Goodale, W. T., and Hellems, H. K.: J. Clin. Invest. 29: 602, 1950.

36. Altschule, M. D.: Acute Pulmonary Edema, Grune and Stratton, 1954.

37. Warren, M. F. and Drinker, C. K.: Am. J. Physiol. 136: $207,1942$.

38. Warren, M. F., Peterson, D.K., and Drinker, C. K.: Am. J. Physiol. 137: $641,1942$.

39. Richter, C. P.: J. Thor. Surg. 23: 66, 1952. 
40. Gibbon, J.H., Gibbon, M. H., and Kraul, C. W.: J. 'Thor. Surg. 12:60, 1942.

41. Gibbon, J.H. and Gibbon, M.H. : Surg. 12: 694, 1942.

42. Wakisaka, J. and Kohno, B.: Rinshō-Geka (Clinical Surgery) 14: 197, 1959 (In Japanese).

43. Drinker, C. K. and Hardenberg, E. : Am. J. Physiol, 156: 35, 1949.

44. Drinker, C. K.: Pulmonary Edema and Inflammation, Harvard University Press, Cambridge, Massachusetts, 1950. 